\title{
Effect of Calligraphy Learning on Moral Education of College Students
}

\author{
Jianbo Ye \\ School of education Hangzhou Normal University, Zhejiang 310000, China \\ Yezhenge001@126.com
}

Keywords: Calligraphy education; moral education; college students.

\begin{abstract}
In order to verify the inherent consistency between the calligraphy art education and the college students' moral education, the principle of the mutual agreement between calligraphy education and moral education is explained. The theoretical model of calligraphy and moral education is set up to reveal the meaning of calligraphy and moral education in primary school. The moral factors in the calligraphy education are analyzed. From the two perspectives of calligraphy teachers' practice of calligraphy education and students' cognition of calligraphy education, the deficiency in calligraphy education is analyzed. The study shows that teachers need to change the guidance of calligraphy education. In addition, it is necessary to reform the methods and evaluation mechanism of calligraphy education, pay attention to the training of calligraphy teachers and improve the current calligraphy teaching.
\end{abstract}

\section{Introduction}

Moral education is the fundamental task of education. Excellent traditional culture can guide young students to enhance national pride and values self-confidence. As an important part of Chinese traditional culture and education, calligraphy education should assume the task of nurturing the core values of socialism, in order to promote the all-round development of young people [1]. Calligraphy is a continuation of the corresponding art form with the continuous development of Chinese traditional culture. Calligraphy education is not just a skill of learning, but also a cultural heritage. In addition, calligraphy education can promote the development of students' moral character. It is a powerful symbol of Chinese culture and the spiritual crystallization. From the perspective of the process and effect of moral education, calligraphic learning also needs to penetrate the elements of aesthetics and emotion. Calligraphy education is carried out in a relaxed, free and active atmosphere [2]. Through writing and practicing, the will of students is tempered. The effective implementation of calligraphy education cannot do without the development of student moral education. The selection of calligraphy teaching materials needs ethical support. The implementation process and effect of calligraphy education are closely linked with the improvement of students' ideological and moral qualities. Calligraphy moral education is different from the general moral education activities. It is necessary to give full play to the cultural and artistic characteristics of calligraphy and promote students' ideological and moral qualities. The factors of moral education in calligraphy education include the image of Chinese characters, cultural connotation and writing training. Although each factor has no direct connection with moral education and ethical behavior, it is closely related to cultural and aesthetic beauty. Therefore, it has the significance of aiding moral education. The potential of moral factors in calligraphy directly determines the hidden characteristics of calligraphy. Because aesthetic objects have the qualities of arousing students' moral conscience, its value of hidden moral education tends to be more effective than moral education. Calligraphy education is an important part of art education. Therefore, its method of moral education is more about using the beautiful image and pleasant experience to overcome the boring morality of "preaching", so that students can naturally lead them into the realm of morality. This is the fundamental difference between the way of calligraphy and moral education and the way of moral education. Calligraphy is a native art in China, which has witnessed the development of history and culture [3, 4]. 


\section{Investigation of Moral Education in College Calligraphy Education}

\subsection{The Method of Calligraphy Moral Education and its Effect}

The way and effect of calligraphy and moral education all show the hidden characteristics. The image of Chinese characters, writing training, the cultural connotation of calligraphy are all effective tools to help moral education [5]. This should reflect the practical character of calligraphy, and be good at giving play to the artistic style of calligraphy. At the same time, it should follow the law of moral development of college students. In order to understand the moral behavior and effect of calligraphy teachers, the corresponding questions were set up in the questionnaire of teachers and students. Chinese character collocation contains the meaning of philosophy and aesthetics, and it is an effective means to use "beauty image" to promote students' perception of experience. According to the results of the survey, the choice of teachers and students does not match. The reasons may be teachers' lectures, but they are not very impressed with the students. Students can only remember how to write, but they can't understand the art of matching Chinese characters. In writing training, the correct posture of the hand can not only help the healthy physical development of the students, but also form a good writing habit. This is also a part of the goal of calligraphy education. In the calligraphy education, writing education is more important than the calligraphy art education, and the writing education has not reached the ideal requirement. Writing education is not only teaching every student to write Chinese characters, but also containing moral elements of writing habits [6]. Teachers may not make full use of this. The comparison between the teachers and the students on the frequency of the collocation of Chinese characters is shown in Figure 1.

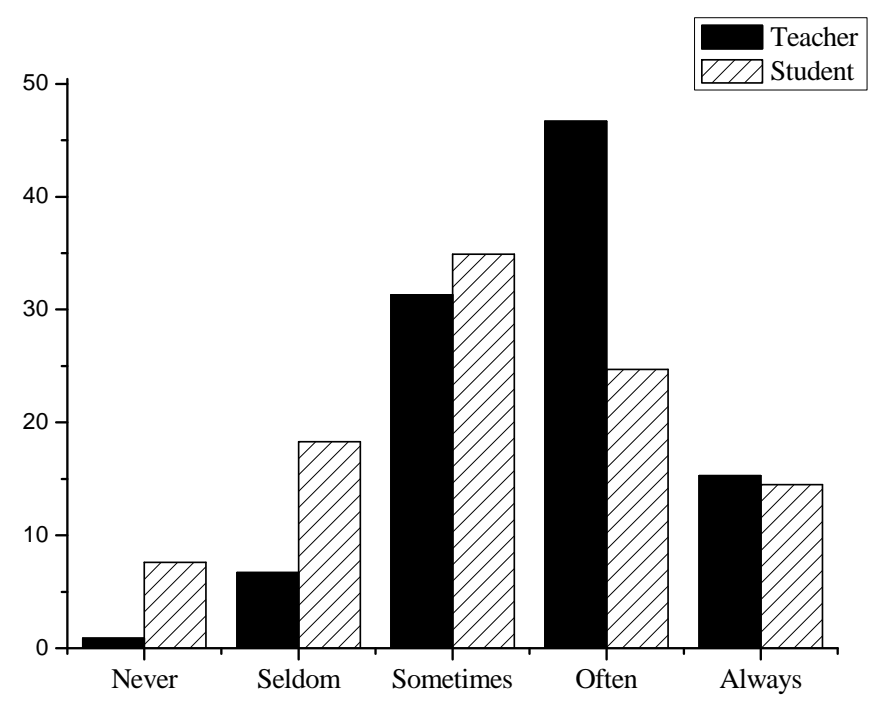

Figure 1. The comparison between the teachers and the students on the frequency of the collocation of Chinese characters

The fundamental role of moral education is to guide the construction of life. To cultivate students' interest in learning calligraphy, it is helpful to cultivate the quality of the students' love of life, to enrich their spiritual life and to improve their interest in life. Teachers may be influenced by subjective initiative, and they tend to choose options that are beneficial to themselves. Because of the pressure of the class, the students seldom have the time to practice calligraphy. However, sometimes, teachers do use some methods to encourage students to love calligraphy, but the effect is not significant. Because of the influence of many aspects, such as parents and schools do not pay attention to calligraphy, students do not have a sense of calligraphy. No matter what kind of reason, it is not conducive to the realization of calligraphy. Teachers teach Calligraphers' life experiences and creative background, which is an important embodiment of calligraphy culture and moral education. Two questions are compared: "you will teach the biographical and creative background of the calligrapher" and "the teacher will explain the biographical experience and creative background of the calligrapher". 
Teachers and students' answers are also mismatched. The effect of calligraphy culture on moral education is shown in Figure 2.

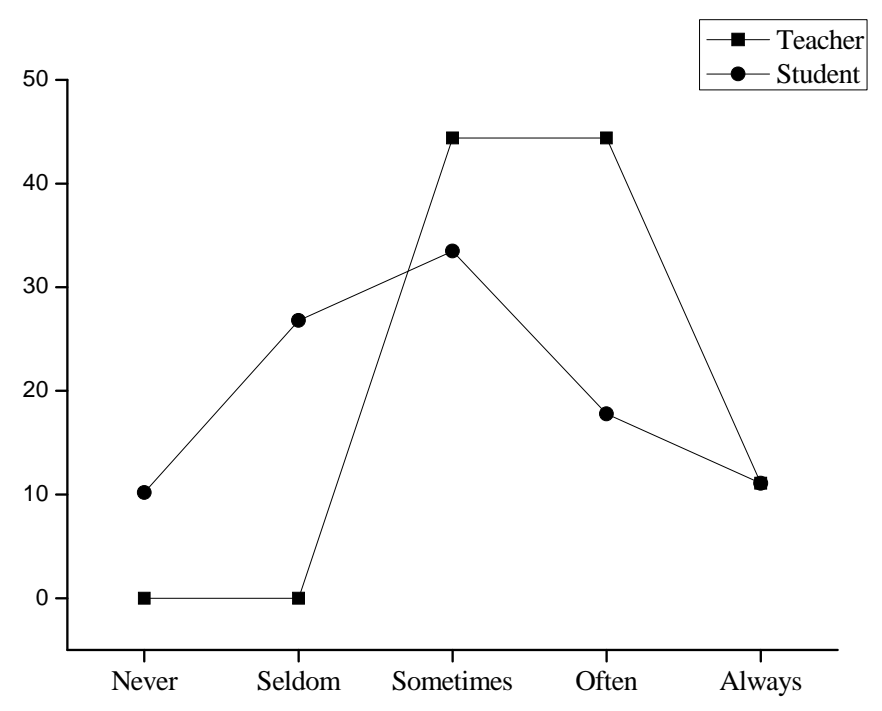

Figure 2. The effect of calligraphy culture on moral education

\subsection{Students' Cognition of Moral Education of Calligraphy Teachers}

In order to get a clear understanding of students' experience and cognition of calligraphy teachers' moral education, this question is set up in the student questionnaire, "if you score for your calligraphy teacher, what do you think he did well?" The results of the specific investigation are shown in Figure 3.

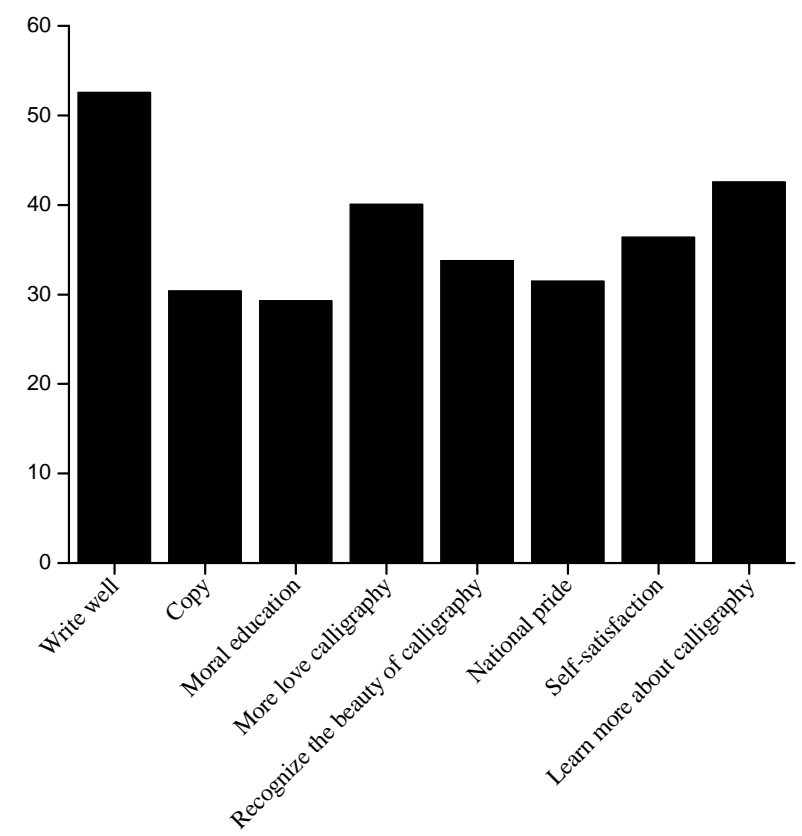

Figure 3. Calligraphy teacher in the eyes of students

As can be seen from the chart, the most frequently chosen words are "written", followed by "learn more about calligraphy" and "prefer calligraphy." Although these three options are more general than the other options, students are more familiar with it. However, it also shows the teacher's emphasis on their education. Among them, the least is the choice of "moral education", which only accounted for $29.3 \%$. The rest, such as national pride education, calligraphy aesthetic education, learning 
attitude education (observation copy) and self-satisfaction education are in the range of 30\% $-37 \%$. In a word, students still have some unfamiliarity with the appearance of these "unconventional words and phrases" in calligraphy education. On the other hand, they show that teachers are not enough to educate national pride and learn attitude education.

\section{The Influence of Calligraphy Education on the Moral Character of Students}

In the teacher's questionnaire, the elements of "calligraphy teachers' cognition of students' thought and morality after learning calligraphy" were set up. $48.9 \%$ of the teachers thought the effect was general, and $42.2 \%$ thought the effect was remarkable, and $8.9 \%$ thought the effect was not significant. No students choose an option that is very significant and basically ineffective. In the student's questionnaire, from the four aspects of calligraphy appreciation, teacher's behavior, calligraphy practice class and campus calligraphy culture, their influence on students' Ideological and moral character is analyzed. Table 1 is the effect of calligraphy appreciation on the development of students' Ideological and moral character. A total of $50 \%$ of the students considered the effect very significant. In the problem of "importance of calligraphy teachers' behavior and behavior to your moral character and behavior", a total of 76.4\% students think that teachers' behavior is very important for their moral development. In the topic of the campus cultural environment, $20.8 \%$ of the students who have not paid much attention to the cultural environment of the campus calligraphy. Only $37.3 \%$ of the students who are concerned about it often have a shock. Although the school created a certain calligraphy atmosphere for the students, the teachers did not fully excavate the moral education resources. These words and paintings have become more and more built on the campus features. In addition, when the students answered "you have a few calligraphy practice activities in a semester", the choice of three and above is $50 \%$. However, the practice of calligraphy does not give full play to the value of human education, as shown in Figure 4.

Table 1 . The effect of moral education in calligraphy appreciation course

\begin{tabular}{|c|c|c|}
\hline Option & Frequency & Percentage \\
\hline Basically, no effect & 23 & 6.5 \\
\hline No obvious effect & 60 & 17.0 \\
\hline has no idea about it & 93 & 26.4 \\
\hline obvious effect & 135 & 38.4 \\
\hline The effect is very remarkable & 41 & 11.6 \\
\hline Total & 352 & 100.0 \\
\hline
\end{tabular}

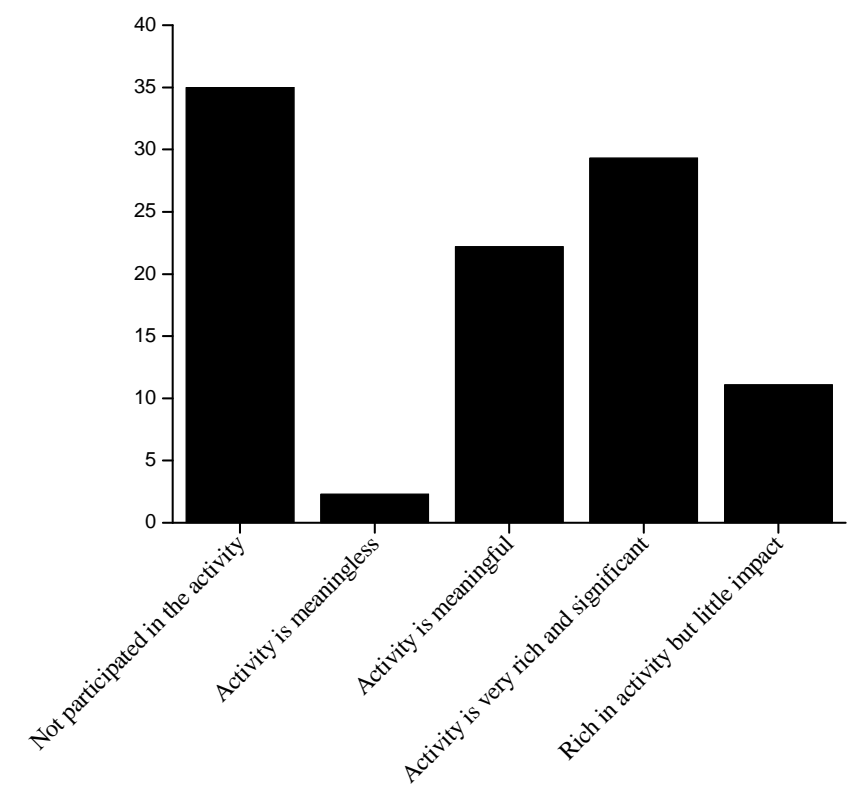

Figure 4. The influence of calligraphy practice on moral character 


\section{Conclusion}

In recent years, the research on the permeation of subject moral education has gradually become a trend, and the basic research paradigm has been formed. However, the theoretical model of moral infiltration in college calligraphy education is not clear. It cannot meet the requirements of the modern and traditional culture education play the theme of morality education. This research will enrich and perfect the theoretical content of calligraphy education in universities, and broaden the research field, which will help reveal the connotation, attributes and bearing modes of calligraphy education. The inner principle of the mutual agreement between calligraphy education and moral education is explained. The related research of calligraphy education in university is conducive to give full play to the value of calligraphy traditional art education, to meet the needs of social development, and to enhance the ideological and moral quality of young people. The development of the moral function of calligraphy helps to change the defects of the current educational model, which provides a valuable reference for the development of school moral education. The present situation of calligraphy and moral education has been explored. The reasons for the low effectiveness of calligraphy education are analyzed. The content of moral education in calligraphy education has been actively excavated. It provides reference for the teaching of calligraphy teachers.

\section{References}

[1]. Matsuo, N. (2016). Outlook of psychological research on morality and moral education: Annual Report of Educational Psychology in Japan, 55, 165-182.

[2]. Zhang, D., \& University, S. (2017). On the innovation of general education and moral education in colleges and universities. Science \& Technology Information.

[3]. Komesaroff, P. A. (2015). Negotiating the moral education of medical students in the age of multiculturalism. Creative Education, 6(4), 472-480.

[4]. Yi, J., \& Chen, Z. (2016). Comparative study on moral education and ideological and political education. Forum on Contemporary Education, 2013(2013), 211-244.

[5]. Lynch, I., Swartz, S., \& Isaacs, D. (2016). Anti-racist moral education: a review of approaches, impact and theoretical underpinnings from 2000 to 2015. Journal of Moral Education, 46, 1-16.

[6]. Lang, L. I. (2015). Analysis on the interaction and integration of piano education and moral education in colleges and universities. Current Research Journal of Social Sciences, 7(1), 16-21. 